\title{
Fazer teatro no CAp-UFRJ: uma experiência compartilhada de produção, iluminação e figurino
}

Luna Becker Schmid*

\section{Resumo:}

Esta pesquisa se refere ao processo do trabalho de bolsistas de figurino, produção e iluminação, do setor de Artes Cênicas do Colégio de Aplicação da UFRJ, no desenvolvimento didático do fazer teatro na escola, com alunos do Ensino Básico. É abordado e descrito o processo pelo qual tais bolsistas usaram como objeto de estudo aprofundando o discurso dialético em suas propostas - que se dá pela arte do diálogo, onde é demonstrado inicialmente uma tese, um ideal ou uma ação argumentados e que através de um debate conjunto se transformam nos conceitos definidos - as escolhas das obras que foram trabalhadas ao longo do ano letivo, suas metodologias, referências e experiências durante o processo até seu desfecho.

\section{Palavras-chave:}

CAp-UFRJ. Artes Cênicas. Produção. Iluminação. Figurino.

\begin{abstract}
:
This research refers to the work of process of clothing scholars, production and lightning, of the Scenic Arts branch from UFRJ's Application Institution, in the school's didactic development towards doing theater, with some students from Basic Education. It is adressed and depicted the process which the scholars utilized as object of study, further developing the dialectic discourse on its purpose - which is given by the art of the dialog, whence is initially shown a thesis, an ideal or a centered action proposal, which through a collective debate, transforms itself into a more definite concepts - the choice of the pieces that were crafted over the academic year, methodology, references and experiences during the process until its outcome.
\end{abstract}

\section{Keywords:}

CAp-UFRJ. Performing Arts. Production. Lighting. Costume.

\footnotetext{
* Graduanda em Artes Cênicas pela Universidade Federal do Rio de Janeiro. E-mail: lunabeckerschmid@gmail.com. ORCID iD: http://orcid.org/0000-0002-7657-9130.

** Bacharel em Direção Teatral pela Universidade Federal do Rio de Janeiro. E-mail: mluisalopesgrimaldi@hotmail.com. ORCID iD: http://orcid.org/0000-0003-1531-8807.
} 


\section{Introdução}

O projeto Laboratório de Produção Teatral na Escola, desenvolvido pelo setor de Artes Cênicas do Colégio de Aplicação da UFRJ (CAp-UFRJ), reúne bolsistas oriundos de diversas graduações, tais como Direção Teatral, Indumentária e Dança, com o objetivo de dar suporte a todos os projetos, espetáculos e atividades pedagógicas desenvolvidas pelos docentes do setor. O Projeto EncenaAÇÃO foi criado no ano de 1997, sendo realizado desde então ao longo de cada ano letivo. Com o objetivo de aprofundar os estudos do processo de ensino de teatro na escola. Desenvolvido com as turmas de $2^{\circ}$ ano do Ensino Médio, é realizado através de aulas regulares com o intuito de aplicar um processo eminentemente pedagógico de montagem de um espetáculo, o qual se divide em duas apresentações teatrais ao longo do ano. A primeira é apresentada no próprio espaço escolar: transformamos a sala de aula no palco no qual o texto escolhido embarca. Esta primeira apresentação, denominada Exercício de Cena, é o contato inicial dos alunos com o palco e o público. Este formato é composto de fragmentos de textos dramáticos e cenas curtas que proporcionam aos alunos a sensação do trabalho com texto e com a dinâmica do fazer teatral. A segunda montagem, de maior complexidade, tem o mesmo nome do projeto, "EncenaAÇÃO", com realização na Mostra de Teatro da UFRJ no final do ano. Nesse caso, é encenada uma peça por completo, com início, meio e fim. Por ser apresentada numa mostra universitária, o profissionalismo e comprometimento com todo o processo desde a montagem até a execução é feito com grande planejamento.

\section{Demanda de produção e figurino}

O trabalho nas áreas de produção e figurino do CAp-UFRJ surgiu em 2005, como resposta às demandas estabelecidas pelo Projeto EncenaAÇÃO, e suas grandes montagens. A partir das necessidades do setor de Artes Cênicas, num primeiro momento a meta era catalogar, organizar e reaproveitar os materiais das montagens anteriores para as futuras apresentações. Com o passar dos anos formou-se um acervo significativo, produto de doações e das próprias produções teatrais, que dispõe desde figurinos, até objetos de cena, adereços e materiais para confecção de novos elementos para as propostas estéticas com o objetivo de atender aos espetáculos apresentados pelos alunos. Assim, dentro das nossas funções está, também, a organização e manutenção do referido acervo. Há no CAp-UFRJ, para além dos demais materiais, um equipamento de iluminação - que dispõe de uma mesa de comando de quatro canais e alguns refletores - e nos cabe, como bolsistas, a organização e catalogação desses materiais, na busca de ações viáveis para a operação e ampliação do mesmo.

Nossa pesquisa se inicia no ano de 2019 onde trabalhamos em conjunto com a equipe de bolsistas diretores, buscando encontrar as melhores soluções de figurino, produção e iluminação, dentro de um orçamento bem limitado, para realizar as criações. A composição dos personagens é feita a partir de customizações e reaproveitamentos dos itens do acervo que já dispomos. Temos, também, peças e objetos trazidos pelos alunos-atores, utilizadas com o intuito de levar à cena uma formulação estética de alta qualidade para atender aos espetáculos. Neste projeto somos incentivados a identificar os problemas e encontrar soluções, o que tornou mais segura a nossa forma de pensar a arte e pô-la em prática. Não só nos capacita como futuros profissionais, diretores, produtores, iluminadores e figurinistas, como também desperta a paixão pela relação pedagógica para com os alunos. Tendo o público jovem como principal estudo, uma das maiores preocupações que colocamos em nossa pesquisa é a relação interpessoal entre a linha de produção/criação e a visão do aluno vinculada ao teatro como um todo, mostrando a importância de cada processo e função dentro de um espetáculo, propondo pequenas construções em conjunto que nos enriquece na concepção dos materiais. 


\section{Montagens em 2019}

Durante a criação conjunta de direção, direção de movimento, figurino, cenografia e iluminação, trazemos em nossas pesquisas um direcionamento determinado com base no tema e contexto abordados no texto escolhido pelas orientadoras do projeto. No primeiro semestre do ano, para o espetáculo Exercício de Cena, foram selecionadas cenas do texto Gota d'Água ${ }^{1}$, de Chico Buarque e Paulo Pontes. A pesquisa debruçou-se não apenas sobre o texto, mas também sobre as referências de montagens anteriores, o que possibilitou novas vertentes criativas. Baseada na tragédia grega Medéia ${ }^{2}$, de Eurípedes, Gota d’Água tece uma intertextualidade onde discute a temática da discrepância social, problematizando a moral e o lugar das classes na sociedade. Aborda a falácia utópica da meritocracia e a pirâmide da desigualdade, pondo em evidência falsos discursos inflados que sustentam as bases do atual sistema. Na versão de Chico Buarque e Paulo Pontes, Medéia se transforma na desafortunada Joana e Jasão estampa um sambista que compõe o sucesso "Gota d’Água" que dá nome à peça. Colocando como universo principal a

[...] combinação dessas diversas mídias - a dança e a música do candomblé, a interferência do rádio e do jornal na vida das pessoas, o coro das vizinhas fofoqueiras, a coreografia do boato, a canção popular contribui para abrasileirar a tragédia grega e dar a ela novos contornos culturais. (BARROS, 2005/2006).

Para além de seu conteúdo, o texto dos poetas conta com a espontaneidade e brilhantismo dos versos. Entrelaçando rimas, os autores conseguem transformar as limitações da realidade em poesia. Contrabalanceando, tratam temas vindos do âmago dos personagens, transmitindo a sabedoria de vida que enriquece a obra.

A partir do segundo semestre, escolhemos encenar O Rinoceronte ${ }^{3}$, de Eugène Ionesco. Escrito no período após a Segunda Guerra Mundial, o texto narra de maneira absurda/insólita o comportamento sociopolítico que era vivenciado. Fazendo um paralelo, buscamos retratar o presente momento que passamos no nosso país, onde somos atravessados com pensamentos extremistas e discursos de ódio constantemente. A trama do espetáculo é compreendida como uma parábola da invasão do ideal fascista na Europa no século $\mathrm{XX}$, tendo em vista o posicionamento do autor ao referir-se de sua realidade ao comentar sobre a obra.

Lembrei-me de que no curso de minha vida tenho ficado muito impressionado pelo que podemos chamar de correntes de opinião, sua rápida evolução, seu poder de contágio, que é o mesmo de uma epidemia de verdade. Repentinamente as pessoas se deixam invadir por uma nova religião, uma nova doutrina, um novo fanatismo. Em tais momentos testemunhamos uma verdadeira mutação mental. [...] temos a impressão de estarmos vendo monstros - rinocerontes, por exemplo. Ficam com essa mesma mistura de candura e ferocidade, e se tornam capazes de nos matar com a consciência tranquila. (ESSLIN, 1968, p. 163).

Com a escolha dessa obra para ser estudada e apresentada no Projeto EncenaAÇÃO 2019, foi possível abrir uma linha de diálogo com os alunos-atores sobre democracia e as grandes problemáticas sociais, econômicas e culturais que circundam o cotidiano do brasileiro. Assim como o próprio universo cênico já propõe uma desconstrução para o ator como também para o espectador, a linguagem e narração que Ionesco propõe em $O$ Rinoceronte nos abre portas para explorar o incomum e a figura do estranho como potencializadores da montagem. Para tal, a equipe fez uma busca inspirada no movimento do Teatro do Absurdo vindo desde suas primeiras montagens e chegando às mais atuais realizadas em solo brasileiro. Com esta montagem tivemos um trabalho mais denso, levando em consideração o fato de estarmos apresentando a peça por completo, com três turmas diferentes, na qual cada uma apresentava um dos atos.

\footnotetext{
1. Obra originalmente publicada em 1975.

2. Obra datada de 431 a.C. A edição utilizada no projeto foi a seguinte: EURÍPIDES. Medéia, Hipólito, As Troianas. Tradução de

Mário da Gama Kury. 5. ed. Rio de Janeiro: Zahar, 2001.

3. Obra originalmente publicada em 1960, com o título Rhinocéros.
} 


\section{O figurino}

No processo do figurino de Gota d’Água a pesquisa e idealização foi feita totalmente a partir do que já havia disponível no acervo. A base para a concepção dos trajes foi usar estereótipos, por duas razões. A primeira, é relacionada com o formato do Exercício de Cena, em que a apresentação é composta por alguns fragmentos de cenas curtas do texto, apresentadas não necessariamente na ordem escrita originalmente. Ou seja, o espectador precisaria reconhecer de forma rápida aquele personagem e suas características principais e relevantes, sem precisar assimilar a peça completa. E a segunda tem a intenção de ironizar a relação desses estereótipos com a sociedade. Como a obra traz consigo personagens-tipo marcantes, trazer no figurino estas características acentuadas foi uma forma de quebrar paradigmas e promover reflexões. Definidos tais conceitos o trabalho seguiu de forma prática no acervo, nas buscas de peças de mesma paleta de cor harmônica para definir e delimitar grupos, como por exemplo, as vizinhas fofoqueiras, sambistas, ricos e pobres.

Após a primeira apresentação do projeto, começamos os estudos para a segunda etapa do EncenaAÇÃO: encenar a peça completa $O$ Rinoceronte. Primeiro, a equipe como um todo se aprofundou no texto, nas traduções para nosso contexto atual, e na definição de signos e pretensões que queríamos alcançar. Tais propósitos não só foram debatidos entre bolsistas e orientadores como também com os alunos. Era imprescindível idealizar junto a eles essas mensagens que queríamos passar e conseguimos com êxito em termos como "silogismos" e "ideias". Seguindo neste contexto, se torna muito almejado que esse fazer junto pudesse ser aplicado ao figurino, imaginar toda criação juntos, propor oficinas de produção do figurino e trabalhar a dialética, como as referências-chave do Théâtre Du Soleil, e da Companhia Ensaio Aberto que usam as teorias de Meyerhold do "ator operário", as quais trabalham a imersão do ator na construção total de todos os âmbitos e setores responsáveis pelo grande produto final. Desta forma, os alunos teriam contato com todas as etapas do fazer teatral. Infelizmente, em apenas um tempo escolar semanal não foi possível desenvolver esta cocriação da forma ideal, que foi realizada através de conversas e debates diretos relacionando as propostas de ideias e o feedback dos alunos-atores.

O grande desafio do figurino de Rinoceronte, além do cuidado com os significados atribuídos ao momento histórico do país, foi a repetição dos mesmos personagens para atores diferentes, sem tempo para troca de roupa durante a apresentação anulando a possibilidade de repetição de um mesmo figurino, e com um acervo limitado no sentido de não ser possível modificar de forma irreversível as peças do acervo. Mais uma vez, o trabalho com a cartela de cor para cada personagem foi imprescindível a fim de determinar uma identidade visual fácil de ser assimilada, mesmo que um ator tivesse um biotipo totalmente diferente do outro. Estudadas as possibilidades de cores já existentes no acervo, seus possíveis significados e designações para cada corpo e personagem, enfrentamos outro desafio: a transformação de um humano em rinoceronte em cena, aos olhos do público. Neste figurino, foram usados pedaços de retalho, argila verde na caracterização e chifres de rinoceronte feitos de poliuretano. Tais chifres, que estiveram presentes em vários trajes, foram o maior código do figurino, pois além de estarem diretamente ligados ao título da obra, representavam e discerniam as pessoas que se metamorfosearam daquelas que se mantinham com "fé na humanidade".

Neste projeto pudemos perceber e ressignificar a relação do corpo e aparência. Não só de atores, o que é comum na profissão, mas destes alunos, nos quais fomos capazes de reconhecer a linha tênue do processo de mudanças que ocorrem na adolescência com a aceitação de colocar-se à disposição de uma nova personalidade que seria apresentada pelo espetáculo. Nosso foco passou a ser o conforto, no sentido amplo da palavra. Conforto com a imagem de si mesmos que é projetada através de sua caracterização em cena e na relação com o personagem, e também no sentido de roupas confortáveis para qualquer movimento e ação dentro do palco. Evidenciar qualidades que são camufladas ou negadas pela sociedade e encontrar um meio de fazer o aluno se sentir bem como ator envolto naquela persona, fazendo com que explorasse suas virtudes antes vistas como defeitos comparados aos padrões estéticos. Este foi o principal aprendizado ao qual fomos desafiadas. Além de aprender, tivemos a oportunidade de apresentar aos alunos novos olhares, que já existem dentro das Artes Cênicas com relação à indumentária, como por exemplo que figurinos tem o papel de servir à cena. Viajar através de épocas, transpassar sentimentos, evidenciar grupos, lugares e o mais 
importante: apresentar o perfil, particularidade que aquela figura possui. Este foi o ensinamento partilhado: a capacidade de discernir que esta segunda pele serve não só ao ator, mas principalmente à cena. O respeito pelo papel do figurino e caracterização em relação à cena, e não ao ator. Outro ensinamento foi o respeito que se deve ter pelo instrumento de trabalho desde suas maneiras de cuidado, organização e até preservação.

\section{Iluminação e produção}

Após a contextualização realizada com os alunos sobre o texto a ser abordado, partimos para o campo prático, onde a produção se encaixaria na elaboração da cenografia e iluminação do espetáculo, além da questão programática de ensaios e prazos de resultados. O maior desafio ao atuar na produção, além de precisar estar a par dos meios burocráticos que são requisitados e suprir todas as demandas, é tornar tudo isso pesquisa, elaborando um fio arte-pesquisa-burocracia ao vincular o trabalho aos estudos teatrais. Aquele que está direcionado à função de produzir o projeto de Artes Cênicas EncenaAÇÃO enfrenta durante o ano, as demandas de prazos, presença em todas as pesquisas vinculadas ao projeto central como auxílio, organização de eventos e fóruns acadêmicos, montagem de planilhas de gastos relativos à construção dos espetáculos e demais gastos com o setor, cronograma de ensaios e eventos que compõem o calendário escolar, elaboração/atualização das listas de conteúdo dos acervos de iluminação e objetos cênicos/cenário, elaboração de mídias e administração de páginas e convites digitais sobre os espetáculos além da captação de registros e gerenciamento dos mesmos. Seguindo esse direcionamento, elaboramos, também, uma pesquisa de mídias e divulgação controlada dos resultados das montagens onde o público consegue acessar um breve resumo da obra escolhida para apresentação, registros, fichas técnicas, contextualização para aquela determinada escolha, além das datas, locais e horários em que ocorrerão as apresentações e demais informações relacionadas ao mesmo utilizando as plataformas digitais como Facebook e Instagram e, também, folders e cartazes de autoria da produção (bolsista). A cada espetáculo, contávamos com uma equipe de contrarregragem, composta pelos bolsistas e orientadores, que realizava a montagem e desmontagem de cenário, camarim, iluminação e demais demandas respeitando as normas de segurança e restantes regras que o evento Mostra de Teatro da UFRJ exigia, além de montar um conteúdo de mídias registrado no decorrer das apresentações. É realizado, então, um trabalho técnico de companhia adaptado para a escola.

No espaço escolar há uma série de restrições e barreiras que dificultam a realização de montagens. Nesse momento, as pesquisas começam a adentrar o âmbito da prática. Tudo aquilo que não se vê dentro das coxias. Tendo o público jovem como foco, uma das maiores preocupações que colocamos em estudo foi a relação interpessoal entre a linha de produção/criação e a visão do aluno vinculada ao teatro como um todo, mostrando a importância de cada processo e função dentro de um espetáculo, propondo pequenas experimentações criativas em conjunto. Tornou-se uma composição paralela entre professores, bolsistas universitários e alunos do Ensino Médio.

Baseados nas técnicas de biomecânica no teatro de Meyerhold que aplica a busca de uma tradição teatral e seus reflexos nos dias de hoje, criando um vínculo entre as ações cotidianas, as práticas teatrais e as abordagens construtivas onde as atuações dos atores ultrapassava os palcos. Deste modo, os trabalhos de contrarregragem e demais atuações na estrutura de um espetáculo eram estimuladas a fim de atingirem um grau de empoderamento em todas as áreas do fazer teatral.

Tendo como referência a companhia francesa Théâtre Du Soleil, entrelaçamos a construção cenográfica com a improvisação dos atores. Esse mesmo processo foi aplicado à iluminação onde tratávamos da ressignificação da visão dos recursos de luz e cenário, colocando-os como elementos do espetáculo e não como complemento. A iluminação do projeto seguiu uma linha de criação firmada em pesquisas relacionadas à linguagem do teatro do absurdo como frente e ponto de referência além das estéticas que seriam trabalhadas em parceria com o figurino. Pensadas, assim, seguimos o referencial dos métodos de montagem na mesma linha de inspiração, da abordagem coletiva trabalhando a visão do teatro como um todo, onde todos os pilares são importantes para a realização de um bom espetáculo. A luz deixou de ser complemento para 
ser elemento e presença, trazendo significados e profundidade colocando sempre um questionamento que resultava na construção das plantas de iluminação - mapa que aponta os instrumentos que são utilizados, locais de instalação, sequência de operação e demais informações. Questionamentos como "De que maneira o cenário pode contar essa história?" ou "Como posso levar o público para esse lugar?" dentro do direcionamento dialético com o uso da argumentação como ponto de partida. A composição cenográfica se garantiu com o uso de praticáveis pretos que os atores movimentavam e redirecionavam durante o espetáculo afim de encaminhar a visão do espectador à transição de ambientes. Tendo a possibilidade de juntar, colocar um em cima do outro, separar e deslocar, o cenário se tornou prático sem tirar a riqueza dos significados tendo em vista o orçamento reduzido que tínhamos disponível. Além dos praticáveis, foi montada uma janela suspensa num dos quatro lados da arena cênica, proporcionando um olhar diferenciado ao público dependendo de onde fosse visto, além de trazer profundidade e uma característica conatural contrastada à "estranheza" da estrutura cênica, podendo reconhecer uma semelhança ao universo cotidiano.

Após essa troca com o corpo estudantil, a concepção da dinâmica espacial passou a ser construída com o acompanhamento dos ensaios direcionados pelos bolsistas diretores e a realização, finalmente, da ambientação que buscava trazer a realidade para dentro da cena no entrelaçar de luz, cenário e figurino.

\section{Considerações finais}

A partir da necessidade de uma conclusão para a pesquisa, estabelecemos formas de avaliações. A fim de termos o feedback do público, colocamos na entrada do espetáculo panfletos de opinião. Desta forma a cada final de apresentação tínhamos a avaliação em sua maioria positiva sobre nosso trabalho, além das autoavaliações internas feitas pela própria equipe e pelos nossos orientadores através de debates e reuniões. Alcançamos um resultado de excelência e gratificação por parte do público escolar e do próprio corpo docente que esteve presente durante todo processo.

Durante o ano trabalhamos os recursos dialéticos na relação bolsista-alunos, onde se demonstrou uma construção concomitante baseada nas teses que apresentávamos enquanto pesquisávamos sobre os referenciais advindos dos textos teatrais, por meio da argumentação capaz de definir e distinguir com clareza as concepções que se englobou; demonstrando, assim, na prática um teatro além do palco, onde a elaboração de um espetáculo se faz na tecelagem de seus recursos. Luz, figurino e produção ganham significância, relevância e, acima de tudo, qualidade.

Figura 1 - Registro da equipe ao final do espetáculo $O$ Rinoceronte

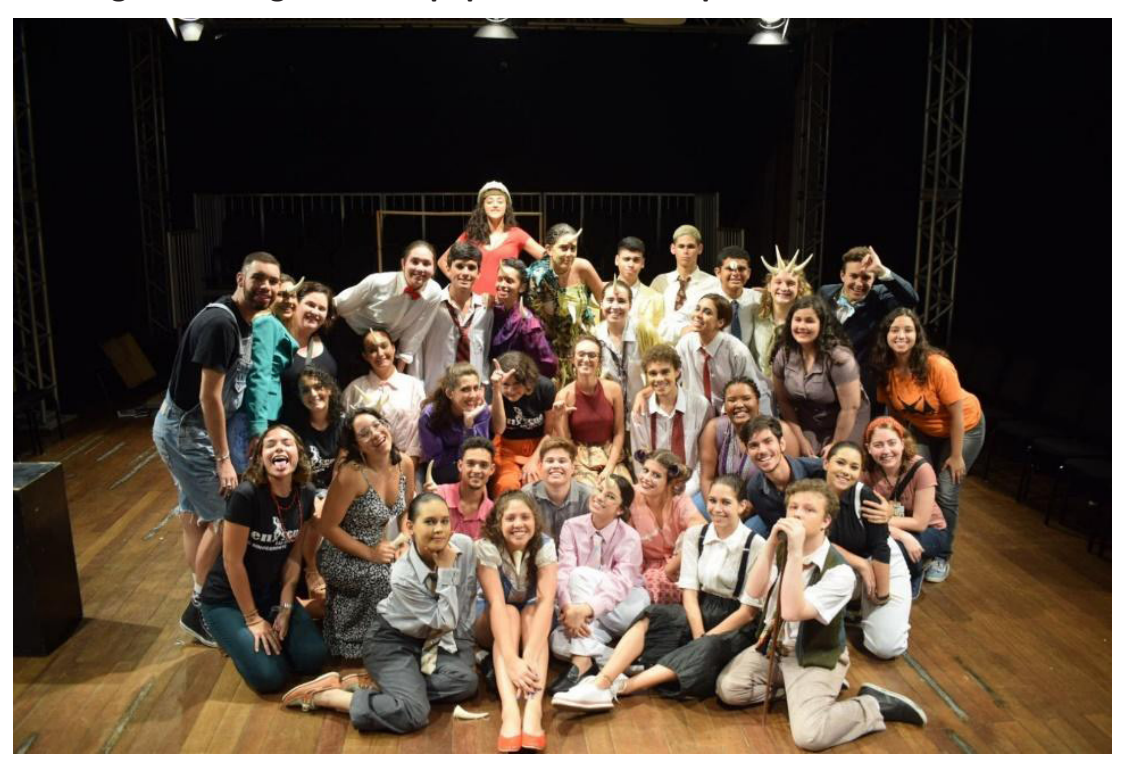

Fonte: Acervo das autoras. 


\section{Referências}

BARROS, Leila Cristina. Tragédia social em Gota d'água, de Chico Buarque e Paulo Pontes: aspectos hipertextuais e intermidiais. Espéculo: Revista de estudios literários, n. 31, Madrid, nov. 2005/fev. 2006. Disponível em: https:// webs.ucm.es/info/especulo/numero31/chicobu.html. Acesso em: 30 maio 2020.

ESSLIN, Martin. O Teatro do Absurdo. Tradução de Bárbara Heliodora. Rio de Janeiro: Zahar, 1968.

Data de submissão: 19/06/2020

Data de aceite: $28 / 07 / 2020$ 